\title{
Signalling by the cleaner shrimp Periclimenes longicarpus
}

\author{
Lucille Chapuis $^{\mathrm{a}, *}$, Redouan Bshary ${ }^{\mathrm{b}, 1}$ \\ ${ }^{a}$ Department of Ecology and Evolution, Biophore, University of Lausanne \\ ${ }^{\mathrm{b}}$ Institute of Biology, University of Neuchâtel
}

\section{A R T I C L E I N F O}

\section{Article history:}

Received 10 September 2009

Initial acceptance 16 October 2009

Final acceptance 7 December 2009

Available online 6 January 2010

MS. number: 09-00586

\section{Keywords:}

cleaner shrimp

cooperative interaction

mutualism

Periclimenes longicarpus

partner control

preconflict management

signal

\begin{abstract}
Signals increase the fitness of a sender by altering the behaviour of receivers. For cooperative interactions biological market theory proposes that signalling strength may be linked to supply and demand. In this context, a recent laboratory experiment demonstrated that cleaner shrimps may advertise their service to client reef fish and that the advertisement is linked to hunger levels. We investigated signalling by the cleaner shrimp Periclimenes longicarpus in the field to test more detailed predictions of biological market theory. Shrimps often clapped with their pair of claws in response to approaching clients. In line with both theory and the previous study, the probability of clapping increased when the shrimps had been food deprived and clapping shrimps were more likely to clean than nonclapping individuals. However, we found no evidence for the market theory prediction that signalling was targeted specifically to visiting client species with the option to choose other cleaning stations. Instead, shrimps signalled more frequently towards predatory clients than towards nonpredatory clients. We conclude that the signal does not serve primarily to attract the choosy clients but to convey information about identity as preconflict management to avoid predation.

(c) 2009 The Association for the Study of Animal Behaviour. Published by Elsevier Ltd. All rights reserved.
\end{abstract}

The mutual interests of cooperative partners may lead them to evolve signals that are reliable by convention (Hasson 1997), to reduce misunderstandings and conflicts (Dawkins \& Krebs 1978). Marine cleaning interactions in which so called cleaners remove ectoparasites from so called clients provide a good model complex of partner species to study signalling in interspecific mutualism (Becker et al. 2005). Client reef fish signal their willingness to be inspected by taking specific postures in front of a cleaner (Côté et al.1998). In turn, the cleaner wrasse, Labroides dimidiatus, is thought to advertise its service to clients by making a 'dancing' movement (Eibl-Eibesfeldt 1955). Shrimps may also clean (Becker \& Grutter 2004), and the cleaner shrimp Urocaridella sp. c advertises with a stereotypical sideto-side movement, or 'rocking dance' (Becker et al. 2005). Becker et al. (2005) described this advertisement signal in the context of a biological market, where two classes of traders exchange commodities to their mutual benefit, and advertise for their services (Noë \& Hammerstein 1995; Becker et al. 2005). In line with biological market theory, the shrimps increased their signalling rate when deprived of food, which indicates low demand for cleaning.

Our objective was to elaborate on Becker et al.'s (2005) laboratory-based study by conducting a field study on signalling in the

\footnotetext{
* Correspondence: L. Chapuis, Department of Ecology and Evolution, Biophore, University of Lausanne, 1015 Lausanne, Switzerland.

E-mail address: lucille.chapuis@gmail.com (L. Chapuis).

1 R. Bshary is at the Institute of Biology, University of Neuchâtel, Emile-Argand 11 Case Postale 158, 2009 Neuchâtel, Switzerland.
}

cleaner shrimp species Periclimenes longicarpus in the Red Sea. During a study on the shrimps' cleaning behaviour (Chapuis \& Bshary 2009), we noticed that the shrimps clapped regularly with one of their pairs of claws (chelipeds) and therefore decided to explore the potential signalling functions of this behaviour in more detail. Our first goal was to test whether we could replicate Becker \& Grutter's (2005) laboratory results under field conditions, by testing how hunger levels affect the shrimps' signalling and cleaning activity. We then asked whether the signal production is linked to a client's option to choose between different cleaning stations. Partner choice is central to biological market theory (Noë 2001) but choice may be overridden by other important parameters, such as a partner's ability to inflict serious costs (Bshary \& Noë 2003). If partner choice is a key determinant of signalling, we predicted that the shrimps should signal more frequently to visiting clients with access to several stations than to resident clients with access to their local station only. If the primary function of signalling is to announce oneself as a cleaner, we predicted that shrimps would signal more frequently to predatory clients than to nonpredatory clients.

\section{METHODS}

\section{Study Site and Cleaning Organisms}

The study was conducted at Mersa Bareika, Ras Mohamed National Park, South Sinai, Egypt. Data were collected between 
September and mid-November 2007. Periclimenes longicarpus is an obligate cleaner shrimp found in the Red Sea and around the Arabian Peninsula and usually lives in groups (Lieske \& Myers 2004). Our 13 study groups ranged from two to 50 shrimps (median $=7$ ). All observations and experiments were done by scuba diving.

\section{Is Clapping a Signal of a Shrimp's Intention to Clean?}

We tested whether clapping was correlated with the probability that a shrimp inspected a client in an experiment in which a diver approached 43 different cleaning stations in total 134 times. At each trial, the diver moved their hand slowly towards a single focal shrimp at a distance of $15 \mathrm{~cm}$ and noted whether or not the shrimp clapped and whether or not the shrimp approached and inspected the hand. We tried to avoid any pseudoreplication by choosing shrimps of different sizes on consecutive visits to the same stations.

\section{General Observation Protocol}

We selected 13 cleaning stations of $P$. longicarpus for convenient accessibility, between 3 and $17 \mathrm{~m}$ in depth, and collected the data while sitting on sandy patches $1.5 \mathrm{~m}$ in front of the station. Observations were done early in the morning and late in the afternoon, corresponding to the time the cleaners were most active (determined during preliminary studies). Each station was observed four times, each session lasting $30 \mathrm{~min}$. Interactions with clients were observed over the entire duration and, immediately afterwards, the following data were written on a Plexiglas plate: (1) client species, as determined according to Lieske \& Myers (2004), (2) client total length, estimated with the help of a reference graduation on the Plexiglas plate, (3) duration of the interactions (s), measured with a stopwatch, and (4) any cleaner shrimp clapping before an interaction.

To test whether clapping occurs more frequently if the shrimps are hungry, we managed to isolate 12 of the 13 cleaning stations for $1 \mathrm{~h}$ each by placing a mosquito net around the station. The net was a siam mosquito net with 156 holes per square inch mesh, and its presence prevented shrimps and client fish from physically interacting with each other. After removal of the net, the station was observed for $1 \mathrm{~h}$. The data were then compared with data from our standard observations.

\section{Data Analysis}

Client species were used as the independent unit. For each client species, the mean values for each cleaning station were summed and divided by the number of stations where the client species had been observed interacting with the shrimps to produce one mean value for client length, duration of cleaning interactions and the probability of clapping.

To test whether clapping occurrence is linked to client choice options, we distinguished between client species that have large home ranges, which cover several cleaning stations, referred to as 'visitor' clients, and species that have small territories and access to only one cleaning station, referred to as 'resident' clients (following Bshary 2001). To test whether clapping occurrence is linked to risk of predation, we distinguished between predatory and nonpredatory client species based on the fish's diet described in Lieske \& Myers (2004).

Data were analysed with the statistical program R ( R Development Core Team, Vienna, Austria). All tests are nonparametric and two tailed.

\section{RESULTS}

\section{Clapping is a Signal of Hunger Levels}

Clapping shrimps came onto the experimenter's hand to clean it significantly more often than nonclapping ones (chi-square test: $\chi_{1}^{2}=11.85, N=134, P<0.01$; Fig. 1 ). In contrast, clapping did not influence interaction duration in our observations (Mann-Whitney $U$ test: $W=16746, N=508, M=63, P=0.55)$. Shrimps clapped 2.3 times more frequently after being isolated for $60 \mathrm{~min}$ than without prior treatment, yielding significant differences (Wilcoxon signedranks test: $W=123, N=13, P=0.03$ ).

\section{Clapping is a Signal Directed Mainly to Predators}

The probability of clapping did not correlate significantly with the clients' size (Spearman rank correlation: $r_{\mathrm{S}}=-0.21, P=0.13$ ). There was also no significant difference in clapping frequency in response to approaching visiting clients compared to approaching resident clients (Mann-Whitney $U$ test: $W=30, N=9, M=8$, $P=0.53$ ). In contrast, the shrimps clapped more frequently when predatory clients approached than when nonpredatory clients approached (Mann-Whitney $U$ test: $W=220, N=25, M=25$, $P=0.04$; Fig. 2).

\section{DISCUSSION}

Our field results confirm an earlier laboratory study that cleaner shrimps signal to clients their willingness to inspect, and that the probability of signalling is linked to the shrimps' hunger level (Becker et al. 2005). In this context, signalling can be seen as an advertisement of service, to improve the exchange of commodities with clients (Noë 2001; Becker et al. 2005). As both the form of signal (clapping versus rocking dance) and the coloration differ between $P$. longicarpus and Urocaridella sp. c, the apparent lack of convergent signalling evolution is opposite to the case of cleaner fish where the vast majority of cleaners have a dark longitudinal stripe on their body (Arnal et al. 2006).

For further consideration of biological market theory, we note that partner choice, the driving force in biological markets (Noë 2001), does not seem to influence the probability of signalling in

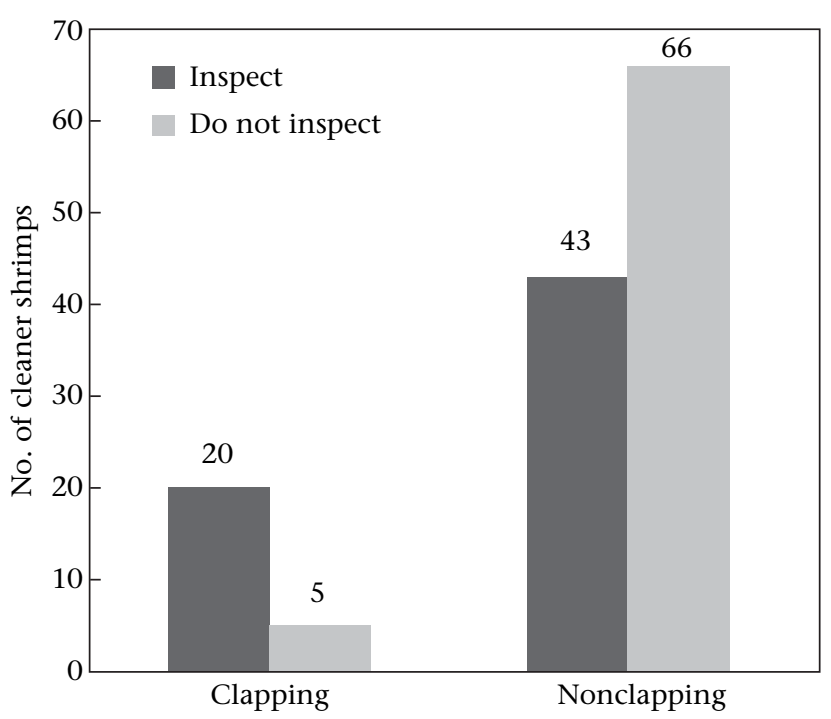

Figure 1. Number of shrimps that inspected or did not inspect the observer's hand after they had clapped or not clapped. $N=134$ observations. 


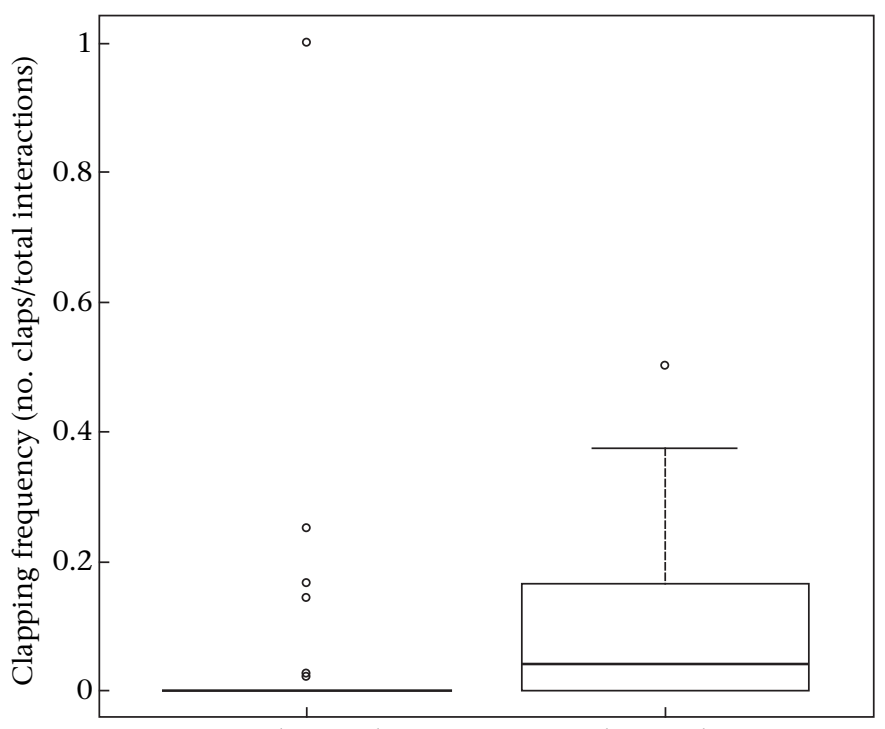

Nonpredatory clients

Predatory clients

Figure 2. Box plots showing the frequency of shrimps clapping/number of interactions with 25 nonpredatory and 25 predatory client species. The boxes show the median and interquartile range, the whisker is 1.5 times the interquartile range and the circles are outliers.

our cleaner shrimps. We also did not find evidence that shrimps signal primarily to particular attractive clients as there was no correlation between clapping and client body size, a measure that should correlate with attractiveness (Bshary 2001).

The frequent occurrence of clapping in the presence of predatory clients suggests that clapping is primarily used as a signal of identity and location (Stummer et al. 2004) that decreases the likelihood that clients mistake the identity of the signaller (Hasson 1997): misidentification by predatory clients could be fatal for the shrimps. Clapping may serve as both visual and auditory/vibration identity signals (Hasson 1997) as many reef fishes have low vision resolution power (Marshall 2000). In contrast to the conspicuously coloured cleaner fish (Potts 1973; Stummer et al. 2004; Arnal et al. 2006), shrimps are often inconspicuous (Jonasson 1987), and our study species is mostly transparent.

In conclusion, the clients' dangerousness seems to override client choice options in determining the shrimps' signalling behaviour. Similar results were found in the cleaner wrasse L. dimidiatus, where service quality is best for predatory clients, apparently to reduce predation risk, rather than for visiting clients with choice options (Bshary 2001; Bshary \& Noë 2003). In baboons, Papio ursinus, Barrett et al. (1999) found that the amount of grooming given or received depends on both choice options and relative rank. Market theory based entirely on supply and demand has helped considerably to improve our understanding of payoff distributions in cooperative interactions (Noë \& Hammerstein 1994; Noë 2001; Johnstone \& Bshary 2008). The next step will be to build a more comprehensive framework that may also explain the limitations of partner choice as a key determinant of behavioural decisions.

\section{Acknowledgments}

We thank Dr Mostafa Fouda, the Egyptian Environmental Affairs Agency and the authorities of Ras Mohamed for permission to work in the national park, and Laurent Keller and Alexandre Roulin for helpful comments and suggestions on the manuscript. We are grateful to Elena Wagner, Sandrine Meyer and Ingo Riepl for assistance during fieldwork.

\section{References}

Arnal, C., Verneau, O. \& Desdevises, Y. 2006. Phylogenetic relationships and evolution of cleaning behaviour in the family Labridae: importance of body colour pattern. Journal of Evolutionary Biology, 19, 755-763.

Barrett, L., Henzi, S. P., Weingrill, T., Lycett, J. E. \& Hill, R. A. 1999. Market forces predict grooming reciprocity in female baboons. Proceedings of the Royal Society $B, 266,665-670$.

Becker, J. H. A. \& Grutter, A. 2004. Cleaner shrimp do clean. Coral Reefs, 23, 515-520 Becker, J. H. A. \& Grutter, A. 2005. Client fish ectoparasite loads and cleaner shrimp Urocaridella sp. c hunger levels affect cleaning behaviour. Animal Behaviour, 70, 991-996.

Becker, J. H. A., Curtis, L. M. \& Grutter, A. 2005. Cleaner shrimp use a rocking dance to advertise cleaning service to clients. Current Biology, 15, 760-764.

Bshary, R. 2001. The cleaner fish market. In: Economics in Nature. Social Dilemmas, Mate Choice and Biological Markets (Ed. by R. Noë, J. A. R. A. M. van Hooff \& P. Hammerstein), pp. 146-172. Cambridge: Cambridge University Press.

Bshary, R. \& Noë, R. 2003. Biological markets: the ubiquitous influence of partner choice on the dynamics of cleaner fish-client reef fish interactions. In: Genetic and Cultural Evolution of Cooperation (Ed. by P. Hammerstein), pp. 167-184. Cambridge, Massachusetts: MIT Press.

Chapuis, L. \& Bshary, R. 2009. High dependency on cleaning interactions and strategic adjustment of service quality in a cleaner shrimp. Animal Behaviour, 78, 455-459.

Côté, I. M., Arnal, C. \& Reynolds, D. 1998. Variation in posing behaviour among fish species visiting cleaning stations. Journal of Fish Biology, 53, 256-266.

Dawkins, R. \& Krebs, J. R. 1978. Animal signals: information or manipulation. In: Behavioural Ecology: an Evolutionary Approach (Ed. by J. R. Krebs \& N. B. Davies), pp. 282-309. Oxford: Blackwell Scientific.

Eibl-Eibesfeldt, L. 1955. Über Symbiosen, Parasitismus und andere zwischenartliche Beziehungen bei tropischen Meeresfischen. Zeitschrift für Tierpsychologie, 12, 203-219.

Hasson, 0. 1997. Towards a general theory of biological signaling. Journal of Theoretical Biology, 185, 139-156.

Johnstone, R. A. \& Bshary, R. 2008. Mutualism, market effects and partner control. Journal of Evolutionary Biology, 21, 879-888.

Jonasson, M. 1987. Fish cleaning behaviour of shrimp. Journal of Zoology, 213 117-131.

Lieske, E. \& Myers, R. 2004. Coral Reef Guide: Red Sea. London: HarperCollins.

Marshall, N. J. 2000. Communication and camouflage with the same 'bright' colours in reef fishes. Philosophical Transactions of the Royal Society B, 355 1243-1248.

Noë, R. 2001. Biological markets: partner choice as the driving force behind the evolution of mutualisms. In: Economics in Nature. Social Dilemmas, Mate Choice and Biological Markets (Ed. by R. Noë, J. A. R. A. M. van Hooff \& P. Hammerstein), pp. 93-118. Cambridge: Cambridge University Press.

Noë, R. \& Hammerstein, P. 1994. Biological markets: supply and demand determine the effect of partner choice in cooperation, mutualism and mating. Behavioral Ecology and Sociobiology, 35, 1-11.

Noë, R. \& Hammerstein, P. 1995. Biological markets. Trends in Ecology E Evolution, 10, 336-339.

Potts, G. W. 1973. The ethology of Labroides dimidiatus (Cuv. \& Val.) (Labridae, Pisces) on Aldabra. Animal Behaviour, 21, 250-291.

Stummer, L. E., Weller, J. A., Johnson, M. L. \& Côté, I. M. 2004. Size and stripes: how fish clients recognize cleaners. Animal Behaviour, 68, 145-150. 